\title{
Efek Penambahan Vitamin E dalam Pengencer Glukosa Fosfat terhadap Daya Tahan Hidup Spermatozoa Domba pada Suhu $5{ }^{\circ} \mathrm{C}$
}

\author{
Nilawati Widjaya \\ Jurusan Produksi Ternak, Fakultas Pertanian, Universitas Bandung Raya \\ Jl. Bukit Raya Bawah, Ciumbuleuit, Bandung, 4014
}

\begin{abstract}
ABSTRAK
Tujuan penelitian ini adalah untuk mengetahui pengaruh penambahan Vitamin E dalam pengencer glukosa fosfat terhadap daya tahan hidup spermatozoa domba pada suhu $5{ }^{\circ} \mathrm{C}$. Penelitian ini menggunakan 3 ekor domba jantan. Rancangan yang digunakan adalah Rancangan Acak Lengkap (RAL) dengan 5 perlakuan dan 4 ulangan, setiap ulangan terdapat 3 ejakulat semen domba. Sebagai perlakuannya adalah Vitamin $E$ dengan dosis $E_{0}=0 \mu \mathrm{g} / \mathrm{ml}, E_{1}=1 \mu \mathrm{g} / \mathrm{ml}, E_{2}=4$ $\mu \mathrm{g} / \mathrm{ml}, \mathrm{E}_{3}=7 \mu \mathrm{g} / \mathrm{ml}$, dan $\mathrm{E}_{4}=10 \mu \mathrm{g} / \mathrm{ml}$. Peubah yang diamati meliputi motilitas, persentase hidup dan keutuhan membran plasma spermatozoa domba. Data dianalisis dengan menggunakan sidik ragam menurut petujuk Steel dan Torrie (1981). Hasil penelitian menunjukan bahwa perlakuan pemberian Vitamin E dengan dosis $1 \mu \mathrm{g} / \mathrm{ml}$ - $10 \mu \mathrm{g} / \mathrm{ml}$ tidak berpengaruh nyata bagi motilitas, persentase hidup dan keutuhan membran plasma spermatozoa domba pada hari ke dua $(\mathrm{P}>0,05)$.
\end{abstract}

Kata kunci: vitamin E, daya tahan hidup, spermatozoa, domba.

\section{Effect of Addition of Vitamin $E$ in Diluent Glucose Phosphate on Live Ability of Sheep Spermatozoa at Temperature $5^{\circ} \mathrm{C}$}

\begin{abstract}
The purpose of this study was to know the effect of vitamin $E$ addition in glucose phosphate diluent on the survival of sheep spermatozoa at $5{ }^{\circ} \mathrm{C}$. The xperiment used 3 rams. The design used was Completely Randomized Design (CRD) with 5 treatments and 4 replicates, each replicate with 3 ejaculate cement of sheep. The treatments were the dose of Vitamin $E$ with $E_{0}=0$ $\mu \mathrm{g} / \mathrm{ml}, E_{1}=1 \mu \mathrm{g} / \mathrm{ml}, E_{2}=4 \mu \mathrm{g} / \mathrm{ml}, E_{3}=7 \mu \mathrm{g} / \mathrm{ml}$, and $E_{4}=10 \mu \mathrm{g} / \mathrm{ml}$. Variables measured were motility, live spermatozoa and plasma membrane integrity. Data were analyzed by using analysis of variance according to Steel and Torrie (1981). The result showed that treatment of vitamin $E$ with a dose of $1 \mu \mathrm{g} / \mathrm{ml}-10 \mu \mathrm{g} / \mathrm{ml} \mathrm{l}$ had no significant effect on motility, percentage live spermatozoa and membrane integrity of sheep spermatozoa on day two $(P>0.05)$.
\end{abstract}

Key words: vitamin E, live ability, spermatozoa, sheep 


\section{PENDAHULUAN}

Dalam pelaksanaan IB diperlukan ketersediaan semen secara kontinyu dan kualitas yang baik. Fertilitas sperma dapat digambarkan dari sejumlah sperma yang hidup dan motil. Untuk memperpanjang daya tahan hidup sperma setelah penyimpanan, perlu dilakukan pengawetan semen. Agar tujuan pengawetan semen dapat tercapai, diperlukan usaha untuk mempertahankan fertilitas dengan menjaga agar tidak terjadi kerusakan keutuhan membran plasma spermatozoa. Untuk itu diperlukan bahan pengencer yang menjamin keutuhan fisik dan kimiawinya dari kerusakan.

Menurut Aurich et al. (1997), salah satu masalah dalam pengawetan semen yang berhubungan dengan penurunan fertilitas adalah kerusakan membran plasma yang disebabkan terbentuknya peroksida lipida akibat adanya oksigen radikal dari proses transport elektron di mitokondria (Hammersted, 1993). Upaya menghambat terbentuknya peroksida lipida dapat dilakukan dengan menambah antioksidan yakni suatu zat yang dapat mengikat senyawa radikal bebas (Wijaya, 1996). Garza et al. (1985), menyatakan bahwa pemberian vitamin E 10 $\mu \mathrm{g} / \mathrm{ml}$ ditambah $50 \mu \mathrm{g} / \mathrm{ml}$ gossypol pada sperma manusia dalam pengencer Krebsringer selama 2 jam dapat terjadi penurunan persentase hidup dari 90,5\% menjadi $62 \%$. Menurut Donoghue dan Donoghue (1997), penambahan vitamin E dalam semen kalkun dapat mempertahankan dan meningkatkan motalitas, persentase hidup, dan keutuhan membran plasma.

Berdasarkan hal tersebut, maka dilakukan penelitian tentang penambahan vitamin $\mathrm{E}$ dalam pengencer glukosa fosfat terhadap motilitas, persentase hidup dan keutuhan membran plasma spermatozoa domba pada suhu $5^{\circ} \mathrm{C}$.

\section{MATERI DAN METODE}

\section{Bahan dan alat}

Bahan yang digunakan dalam penelitian ini adalah semen domba lokal (3 ekor jantan yang berumur kurang lebih 2 tahun), vitamin E merk Natur-E, larutan dasar glukosa fosfat, $\mathrm{NaCl} 3 \%$, eosin supravital, larutan HOS Test (Hipoosmotik Swelling Test), aquadest dan antibiotik penecilin, dan streptomicin.

Alat yang digunakan dalam penelitian ini adalah vagina buatan untuk pengambilan semen, semua pemeriksaan kecuali volume semen digunakan mikroskop, lemari pendingin, kapas, lampu spritus, cover glass, objek glass, pipet, batang gelas pengaduk, counter, pipet haemocytometer, kamar hitung neubaeur dan tabung reaksi.

\section{Rancangan percobaan}

Metode penelitian yang digunakan adalah Rancangan Acak Lengkap (RAL) dengan 5 perlakuan dan 4 ulangan. Setiap ulangan terdapat 3 ejakulat semen domba dan sebagai perlakuan adalah vitamin $\mathrm{E}$ dengan dosis $\mathrm{E}_{0}=0 \mu \mathrm{g} / \mathrm{ml}, \mathrm{E}_{1}=1 \mu \mathrm{g} / \mathrm{ml}, \mathrm{E}_{2}=4 \mu \mathrm{g} / \mathrm{ml}$, $\mathrm{E}_{3}=7 \mu \mathrm{g} / \mathrm{ml}, \mathrm{E}_{4}=10 \mu \mathrm{g} / \mathrm{ml}$. Perubah yang diamati adalah motilitas, persentase hidup, dan keutuhan membran plasma spermatozoa domba.

\section{Data yang diamati dan analisis data}

Data yang dihimpun meliputi volume semen, konsentrasi spermatozoa, motilitas spermatozoa, persentase hidup spermatozoa, dan keutuhan membran plasma spermatozoa. Data dianalisis dengan mengunakan sidik ragam dan bila berpengaruh nyata dilanjutkan dengn uji jarak Duncan menurut petunjuk Steel dan Torrie (1981).

\section{HASIL DAN PEMBAHASAN}

\section{Keadaan Awal Semen}

Kualitas awal semen domba sebelum pengnceran tertera pada Tabel 1. Dari tabel 1 terlihat bahwa kulaitas semen sudah cukup baik tetapi volume semen yang didapat agak rendah yaitu sekitar $0,43 \mathrm{ml}$. Seperti yang di kemukakan Toelihere (1985), volume semen domba berkisar antara 0,5 sampai 2,5 ml 
dengan konsentrasi 1.500 sampai 3.000 juta sel per ml semen dengan 90\% yang hidup. Hal ini diduga karena faKtor frekuensi ejakulasi dimana jarak antara penyadapan pertama dan kedua hanya berselang sebentar. Menurut Salisbury dan Van Demark (1985), factorfaktor yang mempengaruhi kualitas dan kuantitas semen adalah genetik, makanan, libido, temperature, frekuensi ejakulasi, umur dan penyakit.

Secara mikroskopis kualitas semen domba sudah cukup baik yaitu motalitas ratarata $77,08 \%$, persentase hidup rata-rata 83,64\% dan konsentrasi rata-rata 3,41 milyard/ml. Toelihere (1981), menyatakan bahwa domba jantan mempunyai kurang lebih 60 sampai $70 \%$ sperma motil.

\section{Pengaruh Vitamin E Terhadap Motilitas Spermatozoa}

Hasil penelitian penggunaan vitamin $\mathrm{E}$ dalam pengencer glukosa fosfat terhadap motilitas spermatozoa dapat dilihat pada Tabel 2. Motilitas awal spermatozoa domba yaitu 77,08\% kemudian pada hari kedua menurun menjadi $19,17 \%$ pada kontrol. Penurunan motilitas pada hari kedua itu diduga disebabkan karena di dalam pengencer glukosa fosfat tidak adanya zat anti cold shock yaitu lipoprotein dan lesithin sehingga terjadi penurunan motilitas. Hasil analisis ragam menunjukan dalam perlakuan pemberian $\propto$-Tokoferol (vitamin E) tidak berpengaruh nyata dibandingkan dengan control $(\mathrm{P}>0,05)$. Hal ini berarti bahwa penggunaan vitamin $\mathrm{E}$ dalam pengencer glukosa fosfat sampai dosis $10 \mu \mathrm{g} / \mathrm{ml}$ tidak memberikan pengaruh yang nyata terhadap motilitas spermatozoa domba. Keadaan di atas di duga disebabkan karena dosis vitamin E yang ada di dalam pengencer glukosa terlalu kecil dari kebutuhan akan vitamin E yang di kehendaki. Namun menurut penelitian Garza dkk., (1985), menyatakan bahawa penambhan vitamin E $10 \mu \mathrm{g} / \mathrm{ml}$ di tamabah $50 \mu \mathrm{g} / \mathrm{ml}$ gossypol pada sperma manusia dalam pengencer krep-ringer selama dua jam dapat terjadi penurunan persentase hidup spermatozoa domba.
Apabila ditilik secara biologis penambahan vitamin $E$ dalam pengencer glukosa fosfat terhadap motilitas spermatozoa pada dosis $1 \mu \mathrm{g} / \mathrm{ml}$ sampai $10 \mu \mathrm{g} / \mathrm{ml}$ ada kecenderungan motilitas. Kecenderungan peningkatan motilitas spermatozoa ini diduga diakibatkan karena viamin $\mathrm{E}$ merupakan antioksidan yang dapat menghambat terbentuknya peroksida lipida. Peroksida lipida dapat merusak membran plasma spermatozoa yang juga berfungsi sebagai sarana transportasi energi dalam bentuk ATP keseluruhan tubuh yang dihasilkan oleh enzim di dalam mitokondria melalui siklus Creb, sedangkan energi ini sangat dibutuhkan untuk pergerakannya. Hal ini sesuai dengan pernyataan Donoghue dan Donoghue (1997), bahwa penggunaan vitamin E sebagai antioksidan dalam semen kalkun dapat mempertahankan dan meningkatkan persentase hidup, motilitas dan keutuhan membrane plasama spermatozoa.

Untuk lebih jelasnya persentase motilitas spermatozoa domba setelah penyimpanan selama 48 jam dapat dilihat pada Gambar 1.

\section{Pengaruh Vitamin E Terhadap Persentase Hidup Spermatozoa Domba}

Hasil penelitian penggunaan vitamin $\mathrm{E}$ dalam pengencer glukosa fosfat terhadap persentase hidup spermatozoa dapat dilihat pada Tabel 3.

Persentase hidup awal spermatozoa domba yaitu 83,64 \% kemudian pada hari kedua setelah perlakuan terjadi penurunan menjadi 29,89 \% pada kontrol. Penurunan sangat drastis, hal ini diduga disebabkan suhu krits dan tidak adanya anti cold shock dalam pengencer glukosa fosfat.

Hasil analisis ragam menunjukan dalam perlakuan pemberian $\propto$-Tokoferol (Vitamin E) tidak berpengaruh nyata dibandingkan dengan kontrol $(\mathrm{P}>0,05)$. Kondisi ini diduga disebabkan karena dosis vitamin $\mathrm{E}$ dalam pengencer glukosa fosfat terlalu kecil dari kebutuhan vitamin E yang dikehendaki. 
Tabel 1. Kualitas Awal Semen

\begin{tabular}{lc}
\hline Kriteria & Rata-rata \\
\hline Volume Semen (ml) & $0,43 \pm 0,14$ \\
Motilitas (\%) & $77,08 \pm 4,50$ \\
Persentase hidup (\%) & $83,64 \pm 4,73$ \\
Konsentrasi (milyard/ml) & $3,41 \pm 1,08$ \\
\hline
\end{tabular}

Tabel 2. Motilitas Spermatozoa Domba setelah Pemberian Vitamin E ( $\propto$-Tokoferol) pada Suhu $5^{\circ} \mathrm{C}$ selama $48 \mathrm{Jam}$.

\begin{tabular}{ll}
\hline Perlakuan & Motilitas (\%) \\
\hline $\mathrm{E}_{0}=0 \mu \mathrm{g} / \mathrm{ml}$ & $19,17 \pm 3,19$ \\
$\mathrm{E}_{1}=1 \mu \mathrm{g} / \mathrm{ml}$ & $20,00 \pm 3,60$ \\
$\mathrm{E}_{2}=4 \mu \mathrm{g} / \mathrm{ml}$ & $20,42 \pm 4,17$ \\
$\mathrm{E}_{3}=7 \mu \mathrm{g} / \mathrm{ml}$ & $22,50 \pm 5,85$ \\
$\mathrm{E}_{4}=10 \mu \mathrm{g} / \mathrm{ml}$ & $24,16 \pm 4,81$ \\
\hline
\end{tabular}

Tabel 3. Persentase Hidup Spermatozoa Domba setelah Pemberian Vitamin E $(\propto$ -Tokoferol) pada Suhu $50^{\circ} \mathrm{C}$ selama $48 \mathrm{Jam}$.

\begin{tabular}{lc}
\hline Perlakuan & Persentase Hidup Spermatozoa (\%) \\
\hline$E_{0}=0 \mu \mathrm{g} / \mathrm{ml}$ & $29,89 \pm 1,85$ \\
$E_{1}=1 \mu \mathrm{g} / \mathrm{ml}$ & $30,87 \pm 3,23$ \\
$E_{2}=4 \mu \mathrm{g} / \mathrm{ml}$ & $31,95 \pm 6,99$ \\
$E_{3}=7 \mu \mathrm{g} / \mathrm{ml}$ & $35,18 \pm 6,62$ \\
$E_{4}=10 \mu \mathrm{g} / \mathrm{ml}$ & $38,48 \pm 2,45$ \\
\hline
\end{tabular}

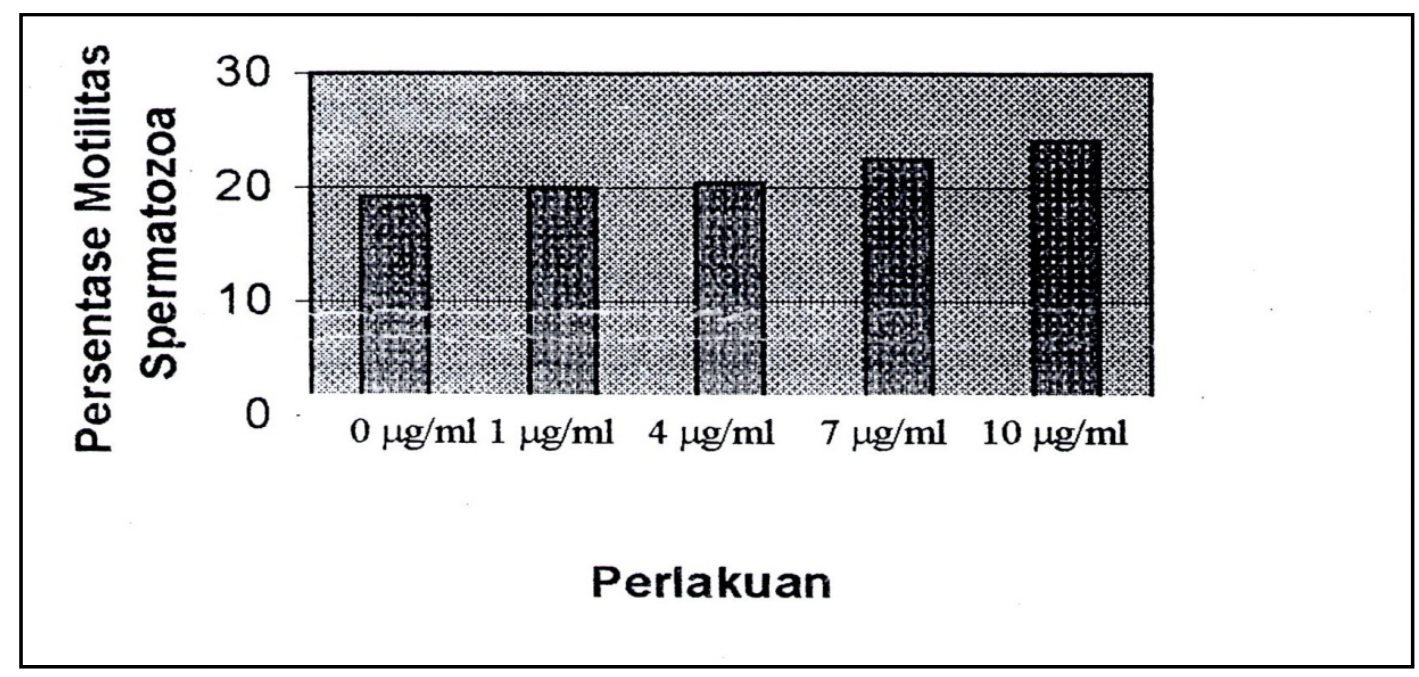

Gambar 1. Persentase Motalitas Spermatozoa Domba setelah Penyimpanan 48 jam 
Faktor-faktor lain yang dapat menurunkan daya tahan hidup sperma adalah kepadatan sperma di dalam medium pengencer, karena metabolisme bertalian erat dengan jumlah sperma hidup. Semakin tinggi konsentrasi sperma hidup, semakin banyak gerakan dan semakin banyak pula metabolism.

Untuk melakukan gerakan sperma memerlukan energi. Energi yang diperlukan melalui kerja enzim di mitokondria yang menggerakan siklus asam trikarboksilat (Siklus Creb), transport elektron fosforilasi oksidatif untuk menghasilkan energi dalam bentuk ATP atau berfungsi merubah fruktosa menjadi asam laktat. Asam laktat yang berlebihan akan mengakibatkan keracunan bagi sperma dan laju kematian makin tinggi. Adanya oksigen radikal sebagai hasil dari proses transport di mitokondria menyebabkan adanya peroksida lipida yang dapat merusak membran plasma spermatozoa. Menurut Aurich dkk., (1997), salah satu masalah dalam pengawetan semen yang berhubungan dengan penurunan fertilitas adalah kerusakan membrane plasma spermatozoa yang disebabkan oleh terbentuknya peroksida lipida. Untuk menghemat terbentuknya peroksida lipida yaitu dengan menambah antioksidan. Vitamin E merupakan antioksidan yang dapat digunakan. Winarno (1991), menyatakan bahwa peranan vitamin E terutama karena sifatnya sebagai zat antioksidan.

Secara biologis penambahan vitamin E dalam pengencer glukosa fosfat terhadap persentase hidup spermatozoa pada dosis 1 $\mu \mathrm{g} / \mathrm{ml}$ sampai $10 \mu \mathrm{g} / \mathrm{ml}$ mengalami peningkatan. Adanya peningkatan persentase hidup spermatozoa disebabkan karena vitamin E ini merupakan antioksidan. Untuk lebih jelasnya persentase hidup spermatozoa domba setelah penyimpanan 48 jam dapat dilihat pada Gambar 2.

\section{Pengaruh Vitamin E Terhadap Keutuhan Membran Plasma Spermatozoa Domba}

Hasil penelitian penggunaan vitamin E dalam pengencer glukosa fosfat terhadap keutuhan membran plasma spermatozoa domba dapat dilihat pada Tabel 4.

Hasil analisis ragam menunjukan bahwa perlakuan pemberian vitamin $\mathrm{E}$ $(\propto$-Tokoferol) dengan dosis $1 \mu \mathrm{g} / \mathrm{ml}$ sampai $10 \mu \mathrm{g} / \mathrm{ml}$ tidak berpengaruh nyata $(\mathrm{P}>0,05)$ dengan kontrol. Hal ini berarti bahwa penggunaan vitamin $\mathrm{E}$ dalam pengencer glukosa fosfat sampai dosis $10 \mu \mathrm{g} / \mathrm{ml}$ tidak memberikan pengaruh yang nyata terhadap keutuhan membran plasma spermatozoa domba. Kondisi ini diduga disebabkan karena dosis vitamin $\mathrm{E}$ dalam pengencer glukosa fosfat terlalu kecil dari kebutuhan vitamin $\mathrm{E}$ yang dikehendaki.

Namun secara biologis penambahan vitamin $\mathrm{E}$ dalam pengencer glukosa fosfat terhadap kebutuhan membran plasma pada dosis $1 \mu \mathrm{g} / \mathrm{ml}$ sampai $10 \mu \mathrm{g} / \mathrm{ml}$ mengalami peningkatan. Peningkatan ini berhubungan dengan fungsi vitamin E sebagai antioksidan. Tomaszewska dkk., (1993), vitamin E berperan di dalam proses mempertahankan integritas bio-membran. Kegiatan ini barangkali berhubungan dengan fungsi vitamin E sebagai antioksidan yang dapat mencegah proses peroksidasi asam lemak tidak jenuh pada membran sel.

Rusaknya permeabilitas atau keutuhan membran plasma menyebabkan cairan intraseluler keluar dan sebagian kepala sperma cenderung mengalami aglutinasi sehingga sperma tidak mampu melakukan pergerakan (White, 1969). Dengan demikian dapat dinyatakan bahwa keutuhan membran plasma sangat penting bagi sperma, karena membran plasma yang rusak tidak dapat diperbaiki (Den Daas, 1992). Keutuhan membran plasma spermatozoa domba setelah penyimpanan 48 jam dapt dilihat pada Gambar 3.

\section{KESIMPULAN}

Dari hasil penelitian dapat disimpulkan bahwa penambahan vitamin $\mathrm{E}(\propto$ -Tokoferol) dengan dosis $1 \mu \mathrm{g} / \mathrm{ml}$ sampai 10 $\mu \mathrm{g} / \mathrm{ml}$ dalam pengencer glukosa fosfat tidak berpengaruh terhadap motilitas, persentase hidup, dan keutuhan membran plasma spermatozoa domba pada suhu $5{ }^{\circ} \mathrm{C}$. 
Tabel 4. Keutuhan Membran Plasma Spermatozoa Domba setelah Pemberian Vitamin E ( $\propto$ -Tokoferol) pada Suhu $50^{\circ} \mathrm{C}$ selama $48 \mathrm{Jam}$.

\begin{tabular}{lc}
\hline Perlakuan & Integritas Membran Plasma (\%) \\
\hline $\mathrm{E}_{0}=0 \mu \mathrm{g} / \mathrm{ml}$ & $37,45 \pm 5,30$ \\
$\mathrm{E}_{1}=1 \mu \mathrm{g} / \mathrm{ml}$ & $39,13 \pm 6,49$ \\
$\mathrm{E}_{2}=4 \mu \mathrm{g} / \mathrm{ml}$ & $40,12 \pm 9,44$ \\
$\mathrm{E}_{3}=7 \mu \mathrm{g} / \mathrm{ml}$ & $44,38 \pm 11,36$ \\
$\mathrm{E}_{4}=10 \mu \mathrm{g} / \mathrm{ml}$ & $46,73 \pm 10,33$ \\
\hline
\end{tabular}

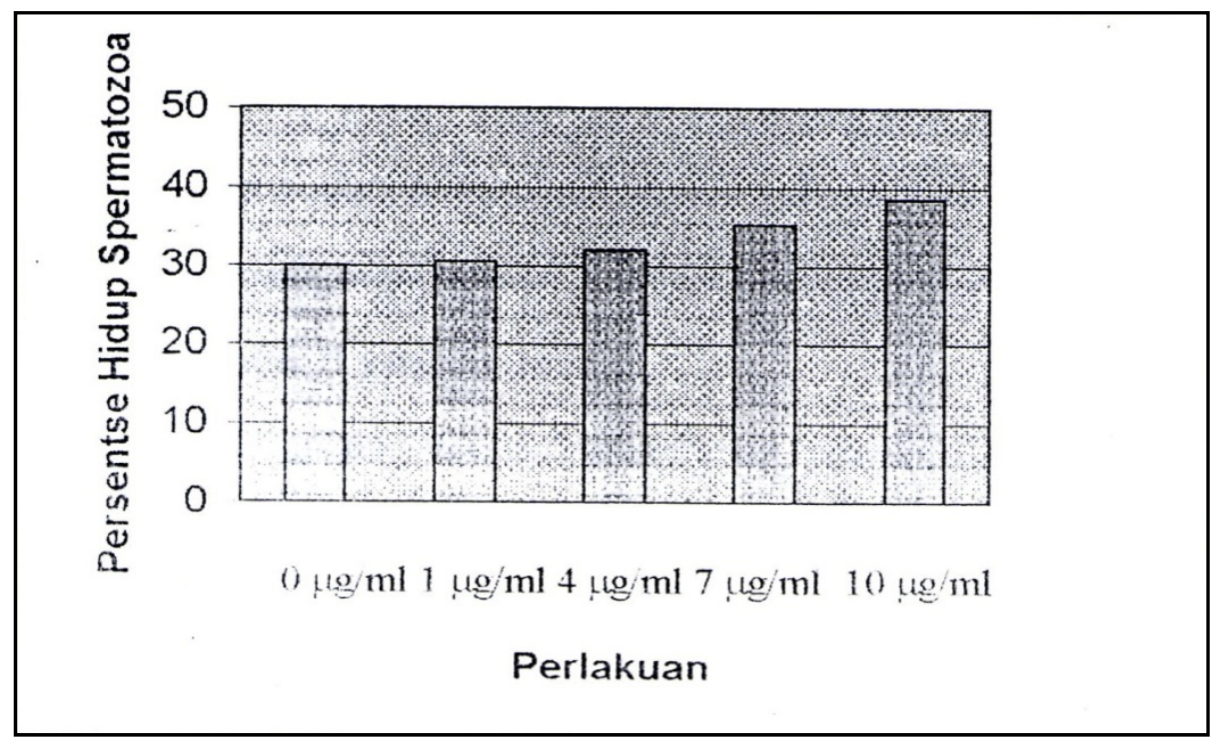

Gambar 2. Persentase Hidup Spermatozoa Domba setelah Penyimpanan 48 Jam

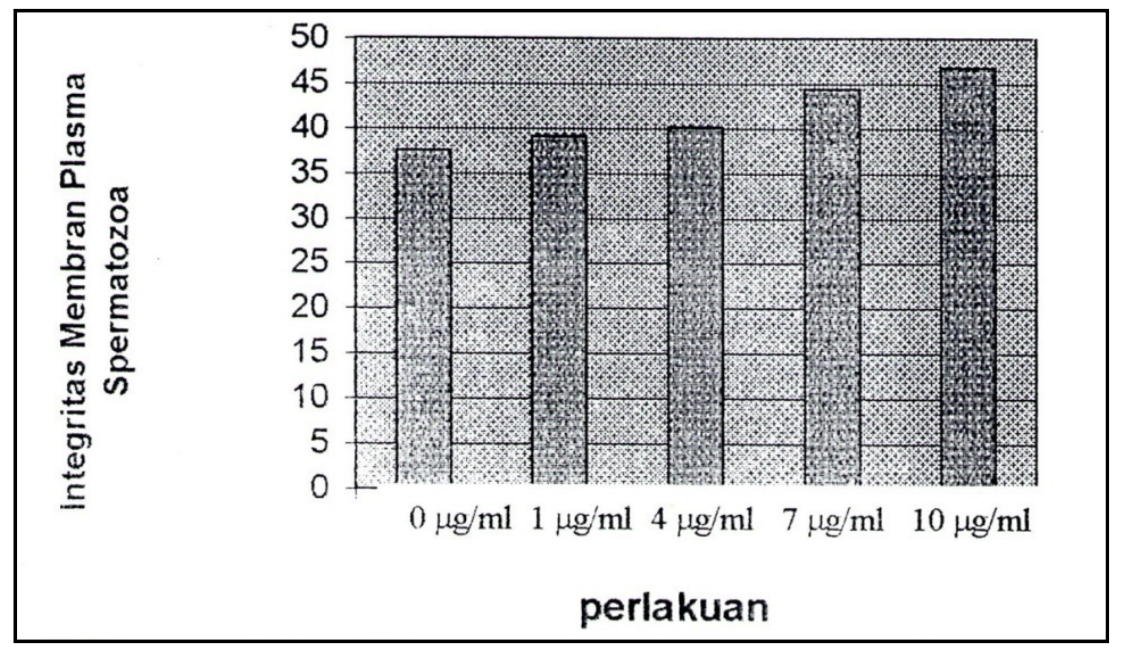

Gambar 3. Keutuhan Membran Plasma Spermatozoa setelah Penyimpanan 48 Jam. 


\section{DAFTAR PUSTAKA}

Aurich, J.E.U. Schon herr.H. Hoppe and C. Aurich. 1997. Effect of antioxidants on motility and membran integrity of chilled stored stallion semen. Theriogenologi 8 : 185192.

Den Daas, N. 1992. Laboratory Assessment of semen Caracteristic. Anim Repro. Sci. 28 : 27-94.

Donoghue, A.M. and Donoghue D.J. 1997. Effects of Water and Lipid Soluble Antioxsidants on Turkey Sprem Viability, Membran Integrity, and Motility During Liquid Storage. Poultry, Sci. $76: 1440-1445$.

Garza, M.T.G. Mantolva, I dan Sotelo, A. 1985. Vitamin E on Human and Rat Lymphocytes and Spermatozoa. Nutrilon reports Internasional.

Hammerstedt, H.R. 1993. Maintemance of Bioenergetic Balance in Spermated Prevantion of Lipid Peroxidation : A Review of The Fertil. Dev. 5 : 675-690.

Salisbury, G.W. and N.L. Van Demark. 1985. Fisiologi dan Reproduksi pada Sapi
(Physiology of Reproducton and Artificial Insemination of Cattle). Terjemahan. Djanuar, R. (ed). Gadjah Mada University Press, Yogyakarta.

Steel, R.G.D. dan J.H. Torie. 1981. Prinsip dan Prosedur Statistik, Suatu Pendekatan Geometrik. Gramedia, Jakarta.

Toelihere, M.R. 1981. Inseminasi Buatan Pada Ternak. Penerbit Angkasa, Bandung.

Toelihere, M.R. 1985. Fisiologi Reproduksi Pada Ternak. Penerbit Angkasa, Bandung.

Tomaszewska, M.W., Mastika, I.M., Djajanegara, A. Gardiner, S dan Wiradarya, T.R. 1993. Produksi Kambing dan Domba di Indonesia. Sebelas Maret Univesity Press, Surakarta.

White, I.F. 1969. Mammalian Semen. Dalam E.S.E. Hafez (ed). Reproduction in Animals. Lea and Febiger. Philadelphia.

Wijaya, A. 1996. Radikal Bebas dan Parameter Status Antioksidan. Forum Diagnosticum.

Prodia Diagnostics Education Servicas, Bandung.

Winarno, F.G. 1991. Kimia Pangan dan Gizi. Gramedia Pustaka Utama, Jakarta. 